\title{
The Impact of Per-Capita Transfer Payment on the Stabilization of Local Fiscal Expenditure
}

\author{
Chongqi He \\ School of Government and Management, Beijing Normal University, Beijing, China \\ Email: 490734381@qq.com
}

How to cite this paper: He, C.Q. (2018) The Impact of Per-Capita Transfer Payment on the Stabilization of Local Fiscal Expenditure. American Journal of Industrial and Business Management, 8, 1101-1112. https://doi.org/10.4236/ajibm.2018.85076

Received: April 21, 2018

Accepted: May 4, 2018

Published: May 7, 2018

Copyright $\odot 2018$ by author and Scientific Research Publishing Inc. This work is licensed under the Creative Commons Attribution International License (CC BY 4.0).

http://creativecommons.org/licenses/by/4.0/

(c) (i) Open Access

\begin{abstract}
The transfer payment should exert the economic and social stability effect. However, the empirical data show that the total amount of transfer payment varies greatly in different regions and deviates from the goal of the transfer payment system to a certain degree. If per-capita transfer payment is adopted as the analysis variable, from 1998 to 2015,31 provincial government financial data were used to empirically test the impact of per-capita transfer payment on the stability of provincial fiscal expenditures. Based on the analysis of the influence of fiscal self-sufficiency and the 5 types of fiscal expenditures closely related to economic and livelihood stability, we can find that the per-capita transfer payment has a significant negative correlation with the stable effect of fiscal expenditure, while the effect of fiscal self-sufficiency on the provincial financial expenditure has no significant effect. Science and Technology Expenditure, Medical Expenditure on the stability of local fiscal expenditure has a more significant negative effect. The influence of Educational Expenses on the stabilizing effect of local fiscal expenditure is not significant. Social Security Expenditure has the same effect as Cultural Expenditure, and has a significant positive impact on the stability of local fiscal expenditure. In order to further enhance the stabilizing effect of transfer payment on local fiscal expenditure, we should improve the current transfer payment system and improve the fiscal expenditure structure of local governments.
\end{abstract}

\section{Keywords}

Per-Capita Transfer Payment, Fiscal Expenditure, Financial Function, Stabilizing Effect

\section{Introduction}

Musgrave (1959) summed up the three functions of modern finance as resource 
allocation function, income redistribution function and stable economic function. For a long time, the academia recognized Musgrave's summary of the modern financial function, that is, the central government should be the best bearer of the responsibility of macroeconomic stability. Since the reform of the tax system in 1994, the central government has established and perfected the intergovernmental transfer payment system to achieve the goal of maintaining economic and social stability, balancing regional financial differences and promoting the equalization of basic services [1]. It is not difficult to find that the current transfer payment system in China, as an important part of the financial system, should play a stabilizing role. With the increasing clarity of the financial function, the rapid growth of the scale of the transfer payment and the improvement of the transfer payment system, the research on transfer payment is flourishing in the academia. However, the research on the effect of the transfer payment system is still focused on the equalization and incentive effects .There are relatively few studies on the stability effect.

The intergovernmental transfer payment is an important tool of fiscal policy, which aims to provide sufficient flexibility for the central government to achieve its macroeconomic stability policy, to pay the necessary political costs for the maintenance of national unity and social stability, as well as unconventional expenditure for the fight against unforeseeable disasters, and so on. The objectives of the transfer payment policy include the goal of the stable effect of the transfer payment, so the current transfer payment should play a role as a stable policy tool, and the study of the stability of the transfer payment system to the local fiscal expenditure is also of great significance. In order to achieve efficiency and fairness, a stable fiscal policy is an essential condition. From the perspective of fiscal expenditure, the flexibility of discretion is reflected in the following aspects. In the economic depression, the local transfer payment is increased to improve the local fiscal revenue to promote and encourage financial expenditure. In the period of economic boom, the transfer payment to the local government should be reduced and the local expenditure can be properly restricted. Finally, the role of the economy should be stabilized.

The research on transfer payment effect in academia is still mainly focused on the effect of public service or financial equalization and the incentive effect of transfer payment on fiscal revenue and expenditure, while the research on the stability effect of transfer payment is relatively few. Based on the academic research, the results of Xu Tao's research are more comprehensive and mature [2]. The conclusion is that the transfer payment has a greater pulling effect on the fiscal revenue and expenditure of the county, the fiscal revenue and expenditure play different roles in the different periods of the economic cycle.

Based on the research results of academia, this paper focuses on the impact of per capita transfer payment on the stability of local fiscal expenditure in 31 provinces except Hong Kong, Macao and Taiwan from 1998 to 2015. At the same time, it joins the index of inter provincial financial self-sufficiency, and 5 kinds of expenditure related to the stability of the economy and the people's live- 
lihood to analyze the stable effect of fiscal expenditure. The purpose of this study is to find out whether the current transfer payment system has played the role of economic and social stability in its setting goals or not, and at the same time, it is expected to be more thorough on the basis of the existing academic research.

In fact, from the relevant data of China Statistical Yearbook and China Financial Statistics Yearbook, it is found that the total transfer payment in the 31 provinces shows a trend of rising year by year, but the base number is not the same as the growth. The total amount of transfer payments shows a big difference either in the province or in the year. From Figure 1, it can be seen that, in addition to a few provinces and regions such as Beijing and Tianjin, during the period from 1998 to 2015, the total transfer payments of the 31 provinces were on a large scale in the time interval, and the differences between different provinces and regions were obvious. Therefore, the total amount of the 31 provinces' transfer payment is not enough to eliminate the characteristics of the larger differences between the regions. In order to further analyze the stability effect of the transfer payment on the provincial and local financial expenditure, this paper uses the per capita transfer payment as an important variable to measure the stability of the transfer payment.

The main innovations of this paper are reflected in the following two aspects. First, by combing the study of transfer payment effect, it is found that there is less attention to the stability effect of transfer payment. Through this study, we choose provincial data for analysis. On the one hand, we can enrich the research on the stability effect of transfer payment on fiscal expenditure. On the other hand, compared with the county level, the provincial government is more macro, which helps to provide empirical support for macroeconomic policy. At the

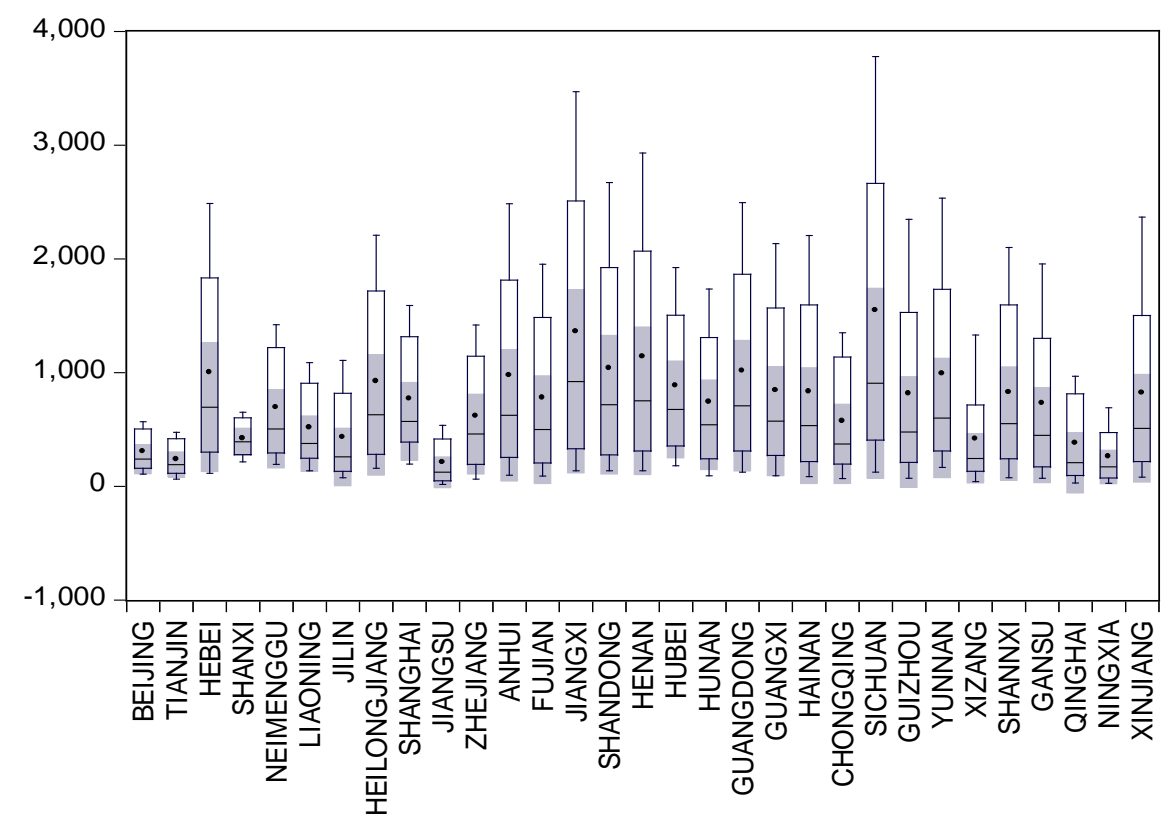

Figure 1. Changes in total transfer payments in 31 provinces across the country (1998-2015). Source: according to the data collected in China's financial Yearbook. 
same time, different from some literatures about the total amount of transfer payment, this paper chooses per capita transfer payment as an important variable to analyze. Considering per capita can reduce the gap between provinces, the empirical results are more practical. However, there are still some limitations in this paper, such as variable selection. It is difficult to quantify the local financial expenditure efficiency, the market index, the scale of the financial expenditure and the change of the transfer payment system, so it is expected that these factors can also be paid attention to in the follow-up study.

The second chapter of this paper is model setting and variable description, which mainly involves the model establishment of the stability effect of per capita transfer payment on local financial expenditure, the definition of the stability effect of transfer payment and the explanatory variables, such as the per capita transfer payment, financial self-sufficiency, science and education and social security expenditure. In the third chapter, based on the empirical model constructed above, the above variables are tested empirically, and the empirical results are obtained, and the possible reasons for such results are analyzed. The fourth chapter is the conclusion and policy recommendations.

\section{Model Setting and Variable Description}

\subsection{The Definition of the Stability Index of Financial Expenditure}

White [3] proposed using unit standard deviation of tax revenue as an indicator of fiscal stability. Pollock and Suyderhoud [4] used the magnitude of volatility around the trend of fiscal spending as an indicator of stability. Hou [5] further developed test methods of Pollock and Suyderhoud's. And then Xu Tao further developed Hou's method. This article draws on Xu Tao's approach to measure the stability of financial revenues and expenditures. EXPGAP = (logarithm of actual fiscal expenditure - logarithm of fiscal expenditure trend value)/logarithm of fiscal expenditure trend value, which is:

$$
\mathrm{EXPGAP}=\left[\ln (\mathrm{EXP})-\ln \left(\mathrm{EXP}^{*}\right)\right] / \ln \left(\mathrm{EXP}^{*}\right)
$$

The fixed effect model is used to calculate the fitting values of actual fiscal expenditures. In order to eliminate the attributes of time series, the natural logarithm is used as the dependent variable of regression. The regression equation is as follows:

$$
\ln \left(\mathrm{EXP}_{i t}^{*}\right)=\alpha_{i}+\beta_{i} T_{t}
$$

Among them, $\mathrm{EXP}_{i t}^{*}$ indicates the trend value of fiscal expenditure in I area in $t$ (fitting value); $T_{t}$ represents the annual value of $t$.

\subsection{Data Source and Index Selection}

This paper mainly studies the effect of per capita transfer payment on the stability of provincial financial expenditure from 1998 to 2015. The related data are from the China Statistical Yearbook, China Financial Statistics Yearbook, and the National City and County Financial Statistics compiled by the budget de- 
partment of the Ministry of Finance and the Treasury Department of the Ministry of finance. The statistical yearbook of China published by the National Bureau of statistics of People's Republic of China is from 1999 to 2016, its statistical data mainly embodies the national economy from 1998 to 2015. Therefore, this paper mainly selects the related data from 1998 to 2015 as the data support of the empirical study.

\subsubsection{Interpreted Variable}

The explanatory variables of this paper are the stability of provincial fiscal expenditure in different regions. If EXPGAP is greater than 0 , it means that the fiscal expenditure is on the rise stage. If EXPGAP is less than 0, it means that the fiscal expenditure is in a downward stage. Counting the statistical data into the (Formula 2.1), the fiscal expenditure of the 31 provinces in the whole country is less than 0 during 1998 to 2015, indicating that the fiscal expenditure of the 31 provinces in the country is in the decline stage. Therefore, the Tobit model is not used to classify the stability of fiscal expenditure into the classification analysis of rising and descending stage, and the fixed effect model can be used for empirical test.

\subsubsection{Explanatory Variables}

Per capita transfer payment. The reason why we choose the per capita transfer payment rather than the total amount of transfer payment to measure its impact on the stability of fiscal expenditure is because the differences in the total amount of the total transfer payments are large and the individual differences are large within the time interval. If the total amount of the transfer payment is taken as an explanatory variable, it cannot eliminate the large difference between regions to a certain extent. When the 31 provinces are taken as the overall analysis, the deviation of the empirical results may be caused by the larger amplitude of individual fluctuation. Based on this, according to the Chinese Statistical Yearbook, China's Financial Statistics Yearbook and other related data, the basic situation of the per capita transfer payment in 31 provinces from 1998 to 2015 (as shown in Figure 2) is analyzed and processed. It is found that, in addition to Tibet and Qinghai, there is a small amplitude of individual fluctuation in each province and the region in the period of the study. This paper chooses the per capita transfer payment as an important index to analyze the effect of the transfer payment on the stability of fiscal expenditure.

In addition to the most important explanatory variable of per capita transfer payment, this article only adds financial self-sufficiency and 5 kinds of expenditures on science and technology, education, cultural services, health and social security, as explanatory variables. First of all, the index of financial self-sufficiency is mainly to investigate the effect of local government's financial income on the stability of local financial expenditure in addition to the transfer of payment. In fact, the academic community generally recognized that the financial self-sufficiency coefficient reacts to the level of financial self development of the provincial 


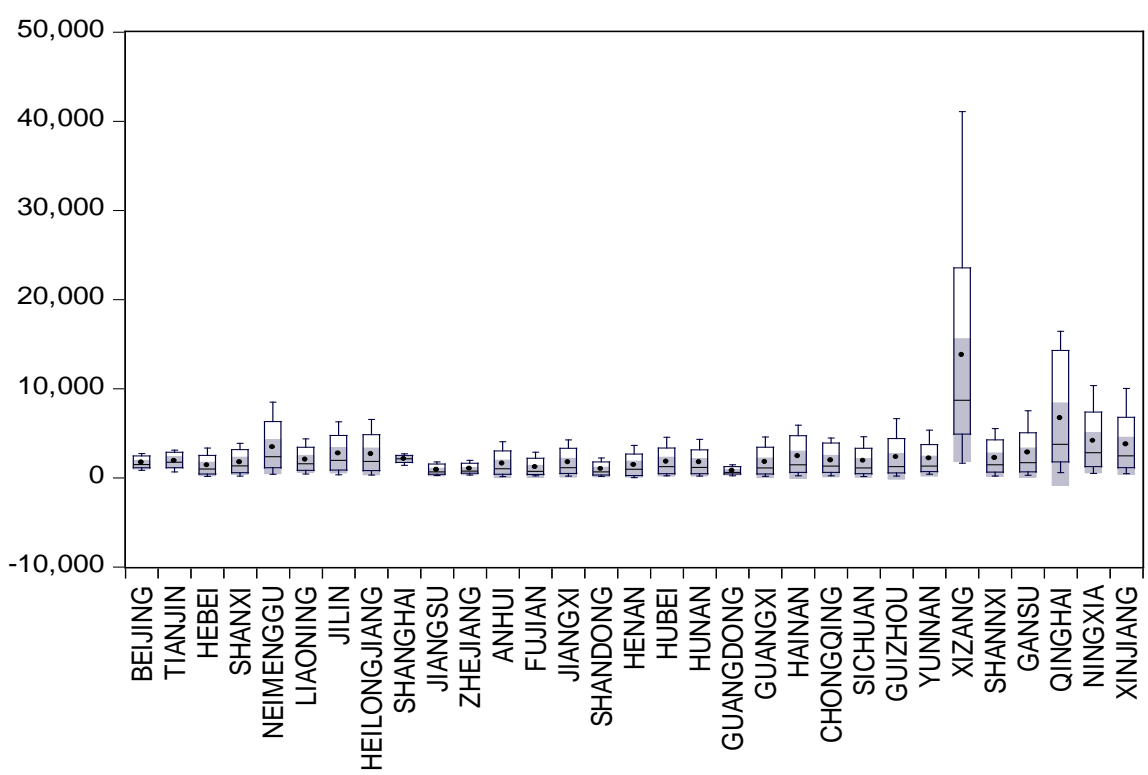

Figure 2. Changes in per capita transfer payments (1998-2015). Source: according to the data collected in China's financial Yearbook.

government. Therefore, this variable can be used to examine whether it should have an important impact on the stability of local fiscal expenditure in theory.

Secondly, this paper chooses different types of financial expenditure, such as science and education, social security and other types of expenditure. On the one hand, science and education and social security are important components of national policy and social life, which are related to the stability of the people's livelihood. On the other hand, the statistical calibre of the Chinese Statistical Yearbook changed from 1998 to 2015. During this period, the statistical types and subjects of science and technology, education, culture, health, and social security were basically stable. Studying the 5 types of expenditure with uniform statistics can maintain the reliability and effectiveness of the data.

At the same time, this paper does not increase the other important variables which affect the financial expenditure. First, some variables have been tested in $\mathrm{Xu}$ Tao's research, such as the rate of financial support, the rate of agricultural population, the total transfer payment, and so on. What's more, it is difficult to quantify the local financial expenditure efficiency, the market index, the scale of financial expenditure and the change of the transfer payment system, so this paper only chooses the per capita transfer payment, the financial self-sufficiency ability and the 5 types of financial expenditure as the explanatory variables.

\subsubsection{Model Setting}

In order to eliminate the time series attributes of the independent variables, all the independent variables use their natural logarithms as the independent variables of the regression. The regression equation is as follows:

$$
\begin{aligned}
\text { EXPGAP }_{i, t}= & \alpha_{i}+\beta_{t}+\gamma_{1} \ln (\mathrm{PTP})+\gamma_{2} \ln (\mathrm{FSR})+\gamma_{3} \ln (\mathrm{STE})+\gamma_{4} \ln (\mathrm{EE}) \\
& +\gamma_{5} \ln (\mathrm{CE})+\gamma_{6} \ln (\mathrm{ME})+\gamma_{7} \ln (\mathrm{SSE})+\varepsilon_{i, t}
\end{aligned}
$$


Among them: $\alpha_{i}$ represents the effect of fixed provinces to control changes in the cross section of the sample, $\beta_{t}$ represents the effect of a fixed year in order to control the effect of time changes in the sample. PTP represents the per capita transfer payment. FSR means financial self-sufficiency. STE indicates the cost of science and technology. EE means education fee. CE expresses cultural undertakings. ME represents health service fees. SSE represents social security expenditure. $\gamma_{1}-\gamma_{7}$ indicates the impact coefficient of per capita transfer payment, financial self-sufficiency, science and technology, education, culture, health, and social security expenditure on the stability of financial expenditure. $\varepsilon_{i, t}$ represents an error term.

\section{Empirical Test and Result Interpretation}

\subsection{Regression Results of Panel Data}

The study used the provincial panel data of 31 provinces and regions from 1998 to 2015 to carry out regression. The results were shown in Table 1 .

\subsection{Analysis of Empirical Results}

\subsubsection{Per Capita Transfer Payment}

The empirical results show that from 1998 to 2015, the stability of the per capita transfer payment to the local fiscal expenditure is significant at the $1 \%$ level, and the coefficient is negative, indicating that the per capita transfer payment has a

Table 1. Regression results of per capita transfer payment to provincial fiscal expenditure (EXPGAP).

\begin{tabular}{cc}
\hline $\begin{array}{c}\text { Dependent variable } \\
\text { regression model }\end{array}$ & EXPGAP \\
Fixed effect model
\end{tabular}

Note: ${ }^{* * *},{ }^{* *},{ }^{*}$ respectively indicate that the estimated coefficients are significant at $1 \%, 5 \%$ and $10 \% ; 2 . t$ values in brackets. 
significant negative impact on the stability of the provincial local fiscal expenditure. As the stability of the fiscal expenditure is less than 0 , the increase in the per capita transfer payment will rise the gap between the actual value of the fiscal expenditure and the trend value of the financial expenditure. That is to say, the stability of fiscal expenditure deviates from the best stability point of 0 . The significant negative impact of per capita transfer payment on the stability of fiscal expenditure is mainly due to the following reasons.

First, as shown in Figure 2, the per capita transfer payment in 31 provinces and regions from 1998 to 2015 shows a more stable state. Since the reform of the tax sharing system, the financial rights and expenditure responsibilities of the central and local governments have been mismatched to a certain extent. The proportion of the central government in fiscal expenditure has declined gradually, from about $30 \%$ in 1994 to less than 15\% in 2013, while the proportion of the local government on the fiscal expenditure has risen year by year. However, because of the mismatch between the financial power and the expenditure responsibility between the local government and the central government, the transfer payment is an important source of the provincial government's financial revenue to some extent, and it is also an important pillar to support the local financial expenditure. The per capita transfer payment in a single region varies little over time, which can increase the predictability of provincial government revenue. Once the local government determines that the province can obtain a small change in per capita transfer payment, it will generate stable financial revenue, so it will maintain the corresponding financial expenditure, so the stability effect of per capita transfer payment for provincial government financial expenditure is significant.

Second, because of the more stable characteristics of the per capita transfer payment, the central government transfer payment system cannot form an effective incentive to the local government's fiscal expenditure. In theory, in the absence of other motives, the increase of the transfer payment will only make the local government's budget constraint shift to the right, and will not produce the effect of distorting the decision-making of the local government's revenue and expenditure. For example, Bradford and Oates [6] believe that the central government's transfer payments or subsidies to local governments are essentially with no difference from the local government's own financial revenues, because different types of income have the characteristics of mutual substitution. However, some scholars have found that the transfer payment is not the same as the local government's own financial income, and the equal transfer payment will increase the local tax rate, and the local government's transfer payment income is not strictly exogenous. When the provincial governments raise tax rates to reduce tax revenue, the central government will increase the transfer payment and financial subsidies to the region for the purpose of equalization. The transfer payment system leads to the increase of local government tax rate and the lack of financial income. The study of Leith and Lewis [7] found that the increase of local government's per capita transfer payment would reduce the efficiency of the 
local government's tax collection, and the local government thought that the transfer payment was free. When the per capita transfer payment is increasing, the local government will produce an incentive to expand the financial expenditure, so the gap between the actual value of the provincial financial expenditure and the trend value of the financial expenditure will be widened.

\subsubsection{Financial Self-Sufficiency}

The empirical results show that the fiscal self-sufficiency ability of local governments cannot have a significant impact on their fiscal expenditure stability effect. In order to show the effect of transfer payment on the stability of local fiscal expenditure more intuitively, Figure 3 shows the degree of dependence on transfer payment in the 31 provincial areas except Hong Kong, Macao and Taiwan in 2016. Among them, the white area represents the non sample area, and the greater the dependence degree of transfer payment is, the more color the picture shows. It can be seen that the dependence of the eastern coastal areas on the transfer payment is the lowest. In 2016, the dependence degree of transfer payment in Shanghai was only 0.07 , and the ability of financial self-sufficiency was the strongest. In the central and western regions, especially in ethnic regions (such as Tibet, Qinghai, Gansu and Guizhou), the dependence of transfer payments is very high, Tibet is 0.875 and Qinghai is 0.698 , which is about 13 times and 10 times that of Shanghai in the same period. The difference in the degree of dependence on payments between regions also reflects the huge difference of fiscal self-sufficiency capacity in different regions. Therefore, the effect of fiscal self-sufficiency on the stability of provincial government expenditure is not significant.

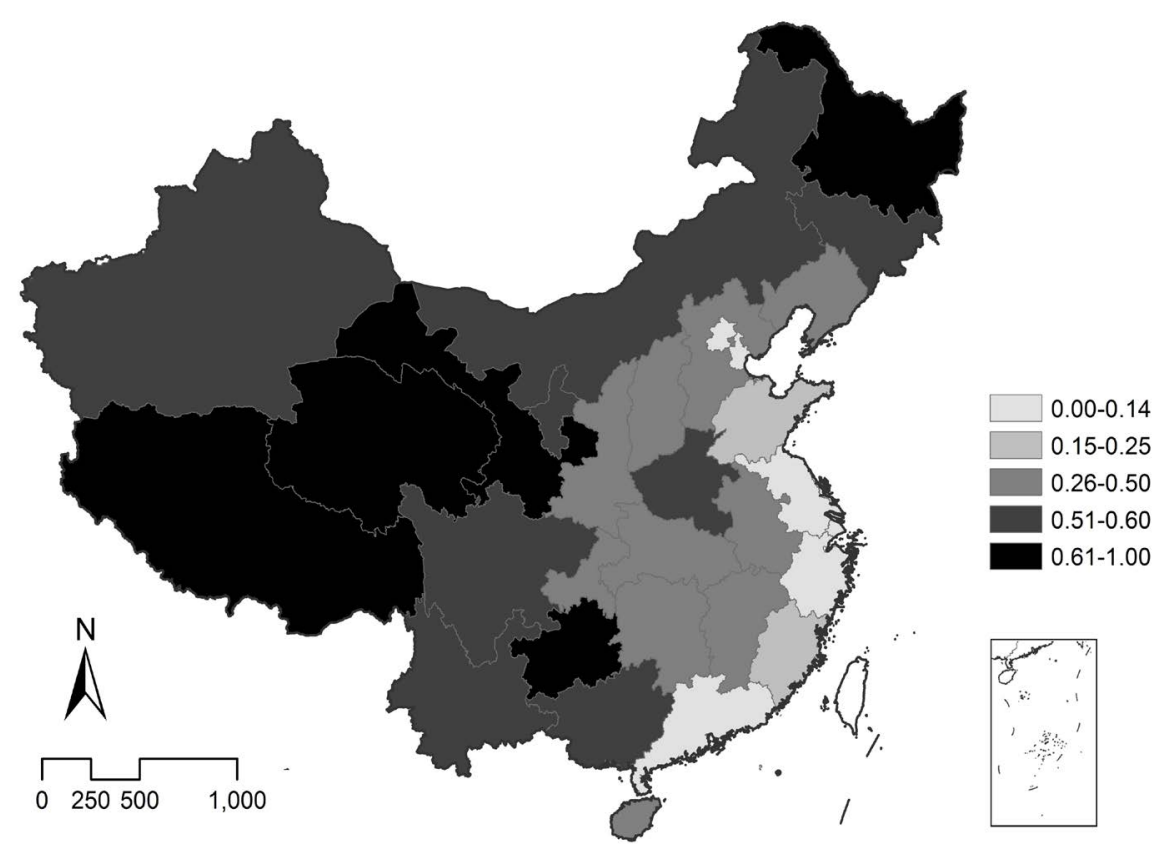

Figure 3. Transfer payment dependency ratio (2016). Source: according to the data collected in China's financial Yearbook. 


\subsubsection{The 5 Kinds of Financial Expenditure}

The empirical results show that the stability effect of science and technology costs on local fiscal expenditure is significant at the $10 \%$ level, and the coefficient is negative, which shows that the scientific and technological cost has a more significant negative effect on the stability of local financial expenditure. The impact of educational expenses on the stability of local fiscal expenditure is not significant. The effect of cultural undertakings on the stability of local financial expenditure is significant at the $1 \%$ level, and the coefficient is positive, which indicates that the cultural cause fee has a significant positive effect on the stability of local financial expenditure. Health expenditure is significant at $1 \%$ level, and the coefficient is negative, indicating that it has a significant negative impact on the stability effect of local fiscal expenditure. Social security expenditure and cultural undertakings have the same effect, which has a significant positive impact on the stability of local fiscal expenditure.

The central government's transfer payment to local governments at the provincial level failed to effectively promote the development and equalization of provincial public services. It may be that the allocation of funds from the central financial transfer payments does not give a good balance to the standards of fairness and efficiency, and local governments with stronger bargaining power will get more transfer payments by pressure. Although the central government emphasizes the fairness of local public health services and science and technology, it ignores the financial incentive and restricts the fairness between them. Therefore, the cost of science and technology and health services have a negative impact on the stable effect of fiscal expenditure. Social security expenditure has a positive effect on the effect of fiscal expenditure stability, probably because of its special nature. From 1998 to 2006, social security expenditure accounted for a small proportion of fiscal expenditure, and increased significantly in 2007, which exceeded $10 \%$ in 2015 . This reflects the central government and local governments' attention to this kind of expenditure, so the increase of social security expenditure will help to narrow the gap between the actual value of fiscal expenditure and the value of the trend, so that the fitting value of the financial expenditure tends to 0 .

\section{Conclusions and Policy Recommendations}

This paper mainly analyzes the effect of per capita transfer payment on the stability of local fiscal expenditure in 31 provinces and regions except Hong Kong, Macao and Taiwan from 1998 to 2015, and analyzes the effect of financial self-sufficiency as well as the 5 types of financial expenditure related to the stability of the economy and people's livelihood. The empirical results show that the per capita transfer payment to the stability of the provincial fiscal expenditure is significant at the $1 \%$ level, and the coefficient is negative. The impact of fiscal self-sufficiency on the stability of provincial fiscal expenditure is not significant. Technical and health business fees have a significant negative effect on the stability of provincial fiscal expenditures, of which the cost of scientific and 
technological undertakings is significant in the $10 \%$ level, and the health service fee is significant on the $1 \%$ level. The effect of educational expenses on local fiscal expenditure is not significant. Cultural undertakings and social security expenditures have significant positive effects on the stability of provincial fiscal expenditure, both of which are significant at the $1 \%$ level.

The importance of the local financial stability function is self-evident. In theory, the intergovernmental transfer payment system can play a role as a stable policy tool, and this study also verifies the effect of fiscal transfer payment on the stability of local fiscal expenditure. However, there are still some shortcomings in the current transfer payment system. It is necessary to further improve the financial system and transfer payment system in order to play the stabilizing role better.

In fact, the central financial transfer payment system cannot give consideration to the principle of efficiency and fairness in the allocation of funds, and there are still some defects in the design of the transfer payment system. The empirical results show that the current transfer payment system does not play an upward role in the decline of fiscal expenditure. Influenced by the traditional financial system factors, the principle of the central transfer payment system is not clear enough. Except to the goal of equalization of financial resources and equalization of public services, it does not emphasize the stability of the central transfer payment system. In addition, transfer payment lacks transparency and normalization in distribution. Taking the tax return as an example, too much consideration of historical factors has not adapted to the changes in financial capacity and economic capacity of various regions in recent years. Not only did it not fully play the role of equalization, but also did not give full play to local fiscal incentives, and even suppressed local financial efforts.

In order to further establish the mechanism of local fiscal stability, the transfer payment system should be reformed. First, the transfer payment system with horizontal and vertical combination should be established. It is more beneficial to make up the financial gap between the regions and improve the imbalance of public service by changing the state of the central government and carrying out the fiscal transfer payment system with a horizontal and vertical combination, so as to achieve the goal of coordinated development between regions. Second, adjust the structure of transfer payment and play a stabilizing role. Since the tax sharing system, the practice of returning taxes to protect local vested interests should be changed. The transfer payment, such as financial transfer payment and special transfer payment, should be appropriately expanded. Third, allocate funds reasonably and strengthen standardized management. Considering the equalization and stability, the "factor law" should be taken as the basic method to determine the transfer payment, and the traditional transfer payment forms such as the return of tax and the subsidy of the original system should be changed. At the same time, we should strengthen the authority of transfer payment management and deal with the phenomenon of embezzlement and congestion. 
The financial expenditure of local government is insufficient for the type of economic and people's livelihood stability. Therefore, it is necessary to improve the structure of local government financial expenditure and play the role of fiscal expenditure on the equalization and stability of local public service. On the basis of perfecting the transfer payment system, we should define more clearly the responsibility of local government to the public products, gradually changing the vicious competition of local government political tournaments since the reform of fiscal tax division, changing the assessment mechanism which think highly of GDP only and the fiscal expenditure structure of local governments will be gradually transformed from the tendency toward infrastructure and administrative expenses to the type of expenditure concerned about the stability of the economy and people's livelihood.

\section{References}

[1] Sun, K. (2009) Research on the Optimization of the Methods of Financial Transfer Payments Integration and Distribution. Finance \& Trade Economics, 7, 45-49.

[2] Xu, T. (2013) An Empirical Analysis of Transfer Payments on the Stability Effect of Local Financial Revenues and Expenditures. China Taxation Publishing House, Beijing.

[3] White, F.C. (1983) Trade-Off in Growth and Stability in State Taxes. National Tax Journal, 36, 103-114.

[4] Pollock, R. and Suyderhoud, J.P. (1986) The Role of Rainy Day Funds in Achieving Fiscal Stability. National Tax Journal, 39, 485-497.

[5] Hou, Y.L. (2005) Fiscal Reserves and State Own-Source Expenditure in Downturn Years. Public Finance Review, 33, 117-144. https://doi.org/10.1177/1091142104271139

[6] Bradford, D.F. and Oates, W.E. (1971) The Analysis of revenue Sharing in a New Approach to Collective Fiscal Decisions. The Quarterly Journal of Economics, 85, 416-439. https://doi.org/10.2307/1885931

[7] Leith, C. and Lewis, S.W. (2013) Fiscal Sustainability in a New Keynesian Model. Journal of Money, Credit and Banking, 45, 1477-1516.

https://doi.org/10.1111/jmcb.12060 